\title{
EVALUASI KEBIJAKAN PENGELOLAAN BADAN LAYANAN UMUM (BLU) PADA PERGURUAN TINGGI
}

\author{
Teguh Rokhmani \\ Universitas Negeri Jakarta \\ e-mail:teguhrokhmani@gmail.com
}

\begin{abstract}
Abstrak
Implementasi Badan layanan Umum (BLU) pada perguruan tinggi memberikan peluang bagi lembaga ini untuk menerapkan manajemen keuangan secara lebih luwes yang menekankan pada produktivitas,efisiensi, dan efektivitas. Penganggaran berbasis kinerja (performance based budgeting) membuat penyusunan dan penerapan tidak hanya berdasarkan input dan proses, tetapi juga output. Evaluasi merupakan tahapan penting kebijakan guna membuat keputusan yang sesuai dalam ranah publik terutama pada perguruan tinggi untuk meningkatkan layanan kepada para pemangku kepentingan (stakeholders). Ada banyak model-model evaluasi kebijakan yang dapat digunakan sesuai dengan jenis kebijakan yang diterapkan.
\end{abstract}

Kata Kunci: Evaluasi, Perguruan Tinggi, BLU

\section{A. Pendahuluan}

Perubahan sistem penganggaran tradisional menjadi penganggaran berbasis kinerja berlaku sejak ditetapkannya Undang-Undang Nomor 17 Tahun 2003 tentang Keuangan Negara dan Undang-undang Nomor 1 Tahun 2004 tentang Perbendaharaan Negara. Pengelolaan keuangan berbasis kinerja ini secara eksplisit tercantum dalam pasal 68 dan pasal 69 UndangUndang Nomor 1 Tahun 2004, yang mana dalam pasal-pasal tersebut instansi pemerintah yang tugas pokok dan fungsinya memberi pelayanan kepada masyarakat (seperti layanan kesehatan, pendidikan, pengelolaan kawasan, dan 
lisensi) dapat menerapkan pola pengelolaan keuangan yang fleksibel dengan menonjolkan produktivitas, efisiensi, dan efektivitas.

Badan Layanan Umum (BLU) menjadi sebutan instansi pemerintah yang menjalankan ketentuan pada pasal-pasal tersebut. Dijalankannya Badan Layanan Umum ini diharapkan menjadi contoh konkret yang menonjol dari penerapan manajemen keuangan berbasis pada hasil kinerja. Sistem penganggaran berbasis kinerja (performance based budgeting) menjadikan penyusunan dan pelaksanaan anggaran tidak hanya berdasarkan input dan proses saja, tetapi berorientasi pada output (hasil kinerja).

Perguruan Tinggi Negeri diizinkan secara penuh untuk menerapkan Pengelolaan Keuangan Badan Layanan Umum (PK-BLU). Pengelolaan keuangan dapat dilakukan lebih fleksibel, dengan mengutamakan produktivifitas, efisiensi, dan efektivitas. Pola pengelolaan keuangan BLU dimaksudkan agar Perguruan Tinggi Negeri sebagai instansi pemerintah dapat meningkatkan pelayanannya kepada pelanggan, dalam hal ini mahasiswa, masyarakat, dan para stake holder. Seluruh dana PNBP yang didapatkan dari mahasiswa, masyarakat, pemberdayaan fasilitas, dan sumber lainnya dapat dikelola secara langsung tanpa harus setor terlebih dahulu ke KPPN. Hubungan ke KPPN dalam bentuk laporan penerimaan dan pembelanjaan.

Menurut Setiawan, perkembangan BLU sejak dicetuskan kali pertama dengan penetapan PP 23 di tahun 2005 dan diperbarui dengan PP 74 tahun 2012 sungguh pesat, baik dari segi jumlah BLU maupun kontribusi ekonomi sosialnya. Sampai dengan tahun 2014, sudah mencapai 141 instansi pemerintah yang menjadi BLU. Pendapatan BLU mencapai lebih dari Rp.24 T di tahun 2013, semakin tinggi persentasenya terhadap PNBP dibandingkan tahun-tahun sebelumnya. ${ }^{1}$ Kondisi tersebut diharapkan mampu meningkatkan peran BLU sebagai agen pelayanan publik yang menonjolkan efisiensi dan produktivitas sehingga kualitas pelayanan publik itu sendiri semakin dirasakan oleh masyarakat.

Agus Setiawan, "BLU: Akuntansi BLU dan Tantangan kedepannya", Dalam http://www.ppkblu. depkeu.go.id/index.php, Diakses 28 Mei 2016. 


\section{B. Evaluasi Kebijakan}

Menurut Owen bahwa "evaluation as the process of making a judgement about the value or worth of an object under review". Hal ini berarti bahwa evaluasi merupakan dari pengambil keputusan tentang nilai atau kekayaan dari suatu objek yang dikaji. ${ }^{2}$ Di sisi lain, Stufflebeam dan Antony mengatakan bahwa evaluasi adalah"the systematic process of delinating, obtaining, reporting and applying descriptive and judgemental information about some object's merit, worth, probity, feasibility, safety, significance andlor equity". Evaluasi merupakan proses yang penggambaran, pencapaian, pelaporan, dan penyajian informasi yang berguna untuk merumuskan suatu alternatif keputusan. ${ }^{3}$

Demikian juga Preskill dan Jones menyatakan"evaluation is all about asking and answering questions that matter about programs, processes, product, policies, and initiatives". Evaluasi adalah semua tentang bertanya dan menjawab pertanyaan yang penting tentang program, proses, produk, kebijakan, dan inisiatif. ${ }^{4}$ Sementara itu, Raphael menyatakan "evaluation is a continuous process of asking questions, reflecting on the answer to these questions and reviewing your on going strategy and action". Hal ini berarti berarti evaluasi adalah proses berkelanjutan dalam mengajukan pertanyaan, mencerminkan pada jawaban atas pertanyaan dan meninjau strategi dan tindakan selanjutnya. ${ }^{5}$

Secara klasik Keeley dan Scoones mengartikan kebijakan sebagai "keputusan-keputusan yang diambil oleh mereka yang bertanggung jawab untuk bidang tertentu. Keputusan ini biasanya dinyatakan dalam bentuk pernyataan atau posisi resmi atas suatu masalah, yang kemudian dijalankan oleh birokrasi." " Menurut Dunn, kebijakan adalah aturan tertulis yang merupakan keputusan organisasi, yang bersifat mengikat, mengatur perilaku dengan tujuan untuk menciptakan tata nilai baru dalam masyarakat. Kebijakan

2 John Owen,Program Evaluation, $3^{\text {rd }}$ edition (NSW: Allen and Unwin, 2006),hlm.9.

3 Daniel L Stufflebeam, dan Antony J Shinkfield, Evaluation Theory, Models and Application (San Fransisco: John Wiley and Sons Inc,2007),hlm.16.

4 Hallie Preskill, dan Natalie Jones,Practical Guide for Engaging Stakeholder in Developing Evaluation Question(Princetown: Robert Wood Johnson Foundation,2009),hlm.3.

5 Baverley Raphael,Evaluation: A Guide for Good Practices, (Sidney: National Youth Suicide Prevention Strategy Evaluation Working Group,2011),hlm.1.

6 J Keeley dan Scoones,I,Understanding Environmental Policy Processes: A Review, (IDS Working Paper,2003),hlm.89. 
akan menjadi rujukan utama para anggota organisasi atau masyarakat dalam berperilaku. $^{7}$

Owen mendeskripsikan" a policy is a general guide to action, an overaching statement that includes a goal and guiding principles for an intervention”. Jadi, kebijakan merupakan petunjuk umum untuk melakukan aksi, sebuah pernyataan yang mengandung tujuan dan petunjuk prinsip untuk sebuah intervensi ${ }^{8}$ Cochran menggunakan definisi kebijakan "as an intentional course of action followed by a government institution or official for resolving an issue of public concern". Sebuah arah tindakan yang sengaja yang diikuti oleh sebuah lembaga atau pegawai pemerintah untuk memecahkan suatu masalah yang penting bagi masyarakat. ${ }^{9}$

Dye menawarkan definisi evaluasi kebijakan sebagai pemeriksaan yang objektif, sistematis, dan empiris terhadap efek dari kebijakan dan program publik terhadap targetnya dari segi tujuan yang ingin dicapai. ${ }^{10}$ Menurut Meter dan Horn, evaluasi implementasi kebijakan publik merupakan tindakan oleh individu masyarakat (atau kelompok) yang diarahkan pada pencapaian tujuan yang ditetapkan dalam keputusan kebijakan sebelumnya. ${ }^{11}$

Sementara itu, menurut Anderson evaluasi implementasi kebijakan adalah kegiatan yang menyangkut estimasi atau penilaian kebijakan yang mencakup substansi, implementasi, dan dampak. ${ }^{12}$ Selanjutnya, Tilaar dan Nugroho mengemukakan evaluasi kebijakan publik mempunyai empat lingkup makna, yaitu evaluasi perumusan kebijakan, evaluasi implementasi kebijakan, evaluasi kinerja kebijakan, dan evaluasi lingkungan kebijakan. ${ }^{13}$

\section{Model-Model Evaluasi Kebijakan}

7 William N Dunn, Pengantar Analisis Kebijakan Publik, (Jogjakarta:Gajah Mada University Press,2003),hlm.115.

8 Owen,op.cit.,hlm.25

9 C.E Cochran,Meyer,L.C.,Carr.,Cayer,N.J.,American Public Policy: An Introduction, $9^{\text {th }}$ edition (Wadssworth:Cengage-Learning,2009),hlm.1-2.

10 Thomas R Dye,Understanding Public Policy (New Jersey:Prentice Hall,1995),hlm.351.

11 Van Meter,Donald S dan Carl E. Van Horn, The Policy Implementation Process: A Conceptual Framework,(Beverly Hills:Sage Publication,1995),hlm.447.

12 James.E Anderson,Public Policy Making,(New York: Holt Rinehart and Winston,2009),hlm.8.

13 Rian Nugroho,Public Policy, (Jakarta: PT. Elex Media Komputindo,2007),hlm.231. 
Sejumlah pakar mengajukan model evaluasi yang dikenal umum yang dapat digunakan untuk berbagai tujuan, di antaranya:

1. Evaluasi Bebas Tujuan (EBT)

Scriven memperkenalkan evaluasi bebas tujuan (goal-freeevaluation), yaitu suatu proses evaluasi kebijakan publik yang mengabaikan sepenuhnya apa tujuan dari kebijakan itu dibuat. ${ }^{14}$ Evaluasi Bebas Tujuan (EBT) bukan hanya mengabaikan,melainkan pula berusaha sebisa mungkin menghindari evaluator tahu ada tujuan tersebut. Dengan tidak mengetahui apa tujuan sebuah kebijakan, maka evaluator terhindar dari bias yang mungkin memunculkan ketidakseimbangan hasil evaluasi. Dengan mengabaikan, evaluator dapat mengetahui hasil aktual dari suatu program,sengaja atau tidak. EBT secara definisi bebas dari tujuan, bukan hanya tujuan kebijakan, melainkan pula tujuan dari evaluator itu sendiri.

2. Model Evaluasi UTOS

UTOS adalah singkatan dari Unit (satuan), Treatment (perlakuan), Observation (hasil), dan Setting (latar). Secara keseluruhan ia diartikan sebagai "saat dimana data dikumpulkan". Istilah UTOS dibuat oleh Cronbach ${ }^{15}$ untuk menggambarkan kalau evaluasi harus dijalankan pada UTOS dari suatu kebijakan. Evaluasi sendiri tidak harus dijalankan pada keseluruhan UTOS karena sebuah kebijakan dapat berskala besar dan mustahil jika dikaji dalam waktu singkat atau bahkan mustahil untuk dinilai secara keseluruhan. Disini satuan kajian bukan lagi populasi, tapi sampel dan Cronbach menyebutnya utos (UTOS ditulis dengan huruf kecil). Sebenarnya Cronbach menulis utoS, yaitu utos dengan $S$ besar, namun untuk kenyamanan membaca utos seluruhnya ditulis dengan huruf kecil. Metode evaluasi yang dipakai dapat dengan cara kuantitatif maupun kualitatif. Jika kuantitatif, metode analisis yang digunakan adalah SEM (Structural Equation Model) atau model sejenisnya yang menguji sebab akibat. Jika kualitatif maka metode yang digunakan adalah grounded theory.

14 M Scriven, Evaluation Bias and Its Control (University California: Berkeley, 1975)

15 L Cronbach,Designing Evaluation of Educational and Social Programs (San Frasisco: JosseyBass, 1982). 
Setelah evaluasi ketercapaian kebijakan dalam utos diperoleh, hasil ini harus digeneralisasi sebelum dapat memberikan penilaian atas seluruh populasi (UTOS). Hasil evaluasi padautos kemudian dibandingkan dengan *utos (baca "star utos"), yaitu utos lainnya di dalam UTOS. Selain dengan *utos, hasil evaluasi utos juga dibandingkan dengan sub-utos, yaitu utos di dalam utos (subsample). Dengan cara ini maka diperoleh gambaran total menegenai efektivitas kebijakan. ${ }^{16}$

3. Evaluasi Demokratis Deliberatif (EDD)

Metode ini diperkenalkan oleh House dan Howe. Evaluasi Demokrasi Deliberatif terdiri dari tiga dimensi, yaitu partisipasi demokratis, dialog untuk masukan partisipan, dan deliberasi untuk sampai pada penilaian bersama. Dimensi partisipasi demokratis adalah dimana evaluator memilih partisipan yang mewakili semua pihakdan mengaturnya agar dapat melakukan evaluasi pada kebijakan dari perspektif yang mereka wakili. Selanjutnya adalah proses evaluasi yang dilakukan masing-masing pihak. Dalam dimensi dialog, para partisipan bertemu dan berdialog tentang hasil yang masing-masing peroleh. Semua pihak harus memberikan suara dan hasil penelitian harus dilakukan dalam satu kesatuan. Dalam dimensi deliberatif, evaluator menarik kesimpulan dengan meninjau semua masukan, memperdebatkannya, merefleksikannya secara mendalam dan akhirnya mencapai kesimpulan yang syah dan dapat dipertahankan.

4. Evaluasi Berbasis Manfaat

Evaluasi berbasis manfaat (EBM) atau utilization focused evaluation adalah metode evaluasi yang diajukan oleh Patton. EBM mirip dengan EDD karena sama-sama bersifat demokratis. Tujuannya agar pemangku kepentingan lebih mungkin memanfaatkan kebijakan. Oleh karena itu, metode evaluasi ini bertolak belakang dengan dengan metode evaluasi EBT. EBM malah tidak melakukan penilaian, tetapi semata mengusahakan agar kebijakan dapat berguna bagi pihak-pihak berkepentingan. ${ }^{17}$

\footnotetext{
16 W.R Shadish,CookT.D,Campbell,D.T,Experimental and Quasi-Experimental Design for Generalized Causal Inference(Boston:Houghton Mifflin,1963).

17 B Kahar,Excerpts from Review of Evaluation Frameworks (SaskatchewanMinistry of Education,2008).
} 
5. Evaluasi Perbedaan (Discrepancy Evaluation)

Penggagas model evaluasi perbedaan ini adalah Malcolm Provus. Evaluasi perbedaan adalah segala pendekatan evaluasi yang menekankan perbedaan antara kinerja sebuah program dan kriteria kecukupan tertentu (misalnya tujuan,sasaran,keadaan ideal). Tujuan dari evaluasi dalam kerangka evaluasi perbedaan antara nilai efisiensi, keluaran dan dampak program terhadap tujuan awalnya (Johnson, 1986). Evaluasi ini disebut evaluasi perbedaan karena mencoba mencari perbedaan antar-efisiensi, keluaran dan dampak suatu program dari tujuan awal program tersebut. Evaluasi model ini termasuk evaluasi rasional, relativistik atau berbasis tujuan karena sangat bergantung pada tujuan awal program yang dibuat oleh aktor yang superior secara hierarki. ${ }^{18}$

6. Evaluasi Pemeliharaan (Countenance Model)

Model evaluasi pemeliharaan merupakaan model evaluasi yang digagas oleh Robert Stake. Model ini menganalisis kongruensi dan kontingensi data menggunakan matriks deskripsi dan matriks penilaian pada anteseden, transaksi, dan dampak dari sebuah program. Stake menganggap bahwa evaluasi harus dilakukan dengan penjelasan sekaligus penilaian secara menyeluruh. Dia mengembangkan model ini dari model bebas nilai dari Scriven. Model pemeliharaan ini terdiri dari 12 langkah yang membentuk interaksi antara evaluator dengan pemangku kepentingan dalam proses penilaian.

Menurut Stake evaluasi disebut responsif jika memenuhi tiga kriteria: (1) lebih berorientasi langsung kepada aktivitas program daripada tujuan program, (2) merespons kepada persyaratan kebutuhan informasi dari khalayak, (3) perspektif nilai yang berbeda dari orang-orang yang dilayani dilaporkan dalam kesuksesan dan kegagalan program.

7. Model CIPP

CIPP merupakan singkatan dari Context, Input, Process dan Product. Model CIPP dikembangkan oleh Stufflebeam untuk mengevaluasi kinerja secara

18 J Edelenbos dan Van Buuren,A., The Learning Evaluation: A Theoritical and Empirical Exploration. Evaluation Review,29(6):591-592,2005,hlm.608. 
keseluruhan dengan mempertimbangkan mulai dari konteks, pemasukan, proses hingga akhirnya pada hasil. Masing-masing komponen memiliki fungsi berbeda. Context berfungsi memberikan keputusan perencanaan, Input berfungsi memberikan keputusan strukturisasi, Process memberikan keputusan implementasi dan Product memberikan keputusan daur ulang.

Evaluasi yang menggunakan model CIPP bekerja secara linier. Evaluator dapat memilih apakah hanya melakukan evaluasi kinerja pada salah satu aspek atau seluruh aspek. Jika evaluator memutuskan mengevaluasi seluruh aspek, perlu diperhatikan bahwa ini memakan banyak waktu.

\section{Badan Layanan Umum (BLU)}

Merujuk Peraturan Pemerintah Nomor 23 Tahun 2005 yang diperbaharui Peraturan Pemerintah Nomor 74 Tahun 2012, pada pasal 1 disebutkan bahwa Badan Layanan Umum (BLU) adalah instansi di lingkungan Pemerintah yangdibentuk untuk memberikan pelayanan kepada masyarakat berupa penyediaanbarang dan/atau jasa yang dijual tanpa mengutamakan mencari keuntungan dandalam melakukan kegiatarnya didasarkan pada prinsip efisiensi dan produktivitas. Selanjutnya, pada ayat 2 disebutkan juga bahwa Instansi yang telah mendapat mandat sebagai Satuan Kerja (Satker) BLU dapat mengelola keuangannya secara fleksibel berupa keleluasaan untuk menerapkan praktik-praktik bisnis yarg sehat untuk meningkatkan pelayanan kepada masyarakat dalam rangka memajukan kesejahteraan umum dan mencerdaskan kehidupan bangsa, sebagaimana diatur dalam Peraturan Pemerintah ini. Sebagai pengecualiandan ketentuan pengelolaan keuangan negara pada umumnya.

Berdasarkan ayat 1 dan 2 pasal 1 sebagaimana termaktub pada peraturanpemerintah tersebut, ada kata kunci yang harus diperhatikan oleh semua instansi pemerintah yang telah mendapatkan mandat sebagai Satker BLU, yaitu harus mengedepankan beberapa prinsip, diantaranya:

1. Efisiensi dan efektivitas. Dalam konteks ini adalah efisiensi dan efektivitas pelayanan masyarakat serta pengamanan aset negara yang 
dikelola oleh instansi terkait. Penggunaan anggaran harus lebih efisien dan efektif sesuai sasaran dan menghasilkan kinerja;

2. Produktivitas. Produktivitas yang dimaksudkan disini adalah bagaimana anggaran negara dapat menghasilkan kinerja. Oleh sebab itu, anggaran yang dikeluarkan harus berbasis kinerja;

3. Fleksibilitas. Fleksibilitas diberikan kepada Satker BLU dalam rangka pelaksanaan anggaran, termasuk pengelolaan pendapatan dan belanja, pengelolaan kas, dan pengadaan barang/jasa. Kepada BLU juga diberikan kesempatan untuk mempekerjakan tenaga profesional non-PNS serta kesempatan pemberian imbalan jasa kepada pegawai sesuai dengan kontribusinya. Dengan demikian, semua pendapatannya dapat digunakan secara langsung tanpa harus dimasukkan terlebih dahulu kepada kas negara;

4. Tidak mengutamakan keuntungan. Merujuk pasal 9 Peraturan Pemerintah Nomor 74 tahun 2012, disebutkan bahwa Badan Layanan Umum dapat memungut biaya kepada masyarakat sebagai imbalan atas barang/jasa layanan yang diberikan. Imbalan yang dimaksud ditetapkan dalam bentuk tarif yang disusun atas dasar perhitungan biaya per unit layanan atau hasil per investasi dana, dengan mempertimbangkan aspek kontinuitas dan pengembangan layanan; daya beli masyarakat; asas keadilan dan kepatutan; dan kompetisi yang sehat;

5. Dapat menerapkan praktik-praktik bisnis yang sehat. Instansi pemerintah yang telah mendapatkan mandat sebagai Satker BLU diperbolehkan membuka bisnis-bisnis yang relevan dengan tugas pokok instansi pemerintah yang bersangkutan.

Adapun tujuan dikeluarkannya Peraturan Pemerintah Nomor 23 Tahun 2005 yang diperbaharui melalui Peraturan Pemerintah Nomor 74 Tahun 2012, adalah untuk meningkatkan pelayanan kepada masyarakat dalam rangka memajukankesejahteraan umum dan mencerdaskan kehidupan bangsa dengan memberikanfleksibilitas dalam pengelolaan keuangan berdasarkan prinsip ekonomi danproduktivitas, dan penerapan praktik bisnis yang sehat. 
Bermula dari tujuan di atas, yaitu untuk meningkatkan pelayanan publik, maka diperlukan pengaturan yang khusus mengenai instansi pemerintah yang melakukan pelayanan kepada masyarakat saat ini. Merujuk pasal 1 ayat 32, Undang-Undang Nomor 1 Tahun 2004 tentang Perbendaharaan Negara, disebutkan bahwa Badan Layanan Umum adalah instansi di lingkungan pemerintah yang dibentuk untuk memberikan pelayanan kepada masyarakat berupa penyediaan barang dan/atau jasa yang dijual tanpa mengutamakan mencarikeuntungan dan dalam melakukan kegiatannya didasarkan pada prinsip efisiensi dan produktivitas.

Berdasarkan definisi dan tujuan terbitnya Peraturan Pemerintah yang mengatur Keuangan Badan Layanan Umum, maka dapat diringkaskan bahwa karakteristik instansi pemerintah yang telah mendapat mandat sebagai Satker BLU diantaranya:

1. Berkedudukan sebagai lembaga pemerintah yang tidak dipisahkan dari kekayaan negara;

2. Menghasilkan barang dan/atau jasa yang diperlukan masyarakat;

3. Tidak bertujuan mencari profit;

4. Dikelola secara otonom dengan prinsip efisien dan produktivitas alakorporasi;

5. Rencana kerja, anggaran dan pertanggungjawabannya dikonsolidasikanpada instansi induk;

6. Penerimaan baik pendapat maupun sumbangan dapat digunakan secaralangsung dengan prosedur sesuai peraturan yang berlaku.

\section{E. Penerapan Model Evaluasi Kebijakan}

Penerapan model evaluasi kebijakan Badan Layanan Umum dapat menggunakan model responsive evaluation. Model evaluasi ini lebih banyak menggunakan data kualitatif untuk mengambil keputusan kebijakan. Responsive evaluation pertama kali diperkenalkan oleh Robert Stake, dalam artikelnya yang berjudul "The Countenance of Educational Evaluation" pada tahun 1967. Menurut Madaus, responsive evaluation digunakan untuk evaluasi formatif ketika ada kasus yang mengindikasikan program tidak dapat mencapai 
hasil optimal. Responsive evaluation juga digunakan dalam evaluasi sumatif, ketika ada orang yang ingin memahami aktivitas pelaksanaan program. ${ }^{19}$
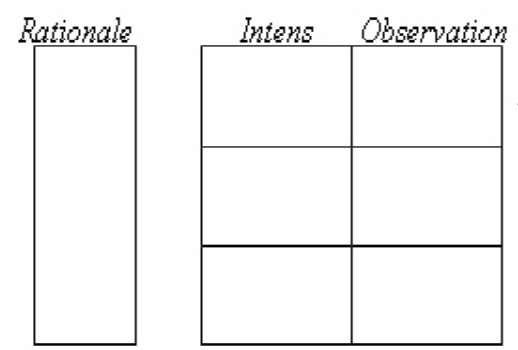

Description

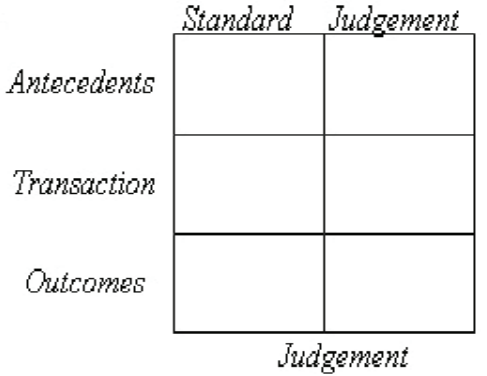

Judgement

Gambar 1. Model Stake's Countenance

Worthen and Sanders memberi penjelasan lebih lanjut tentang informasi yang diperlukan pada responsive evaluation yaitu rational, antecedent, transaction dan outcome. Rational menunjukkan latar belakang filosofi dan dasar tujuan sebuah program. Antecedent, transaksi, dan outcome setara dengan input, proses dan produk. ${ }^{20}$ Data disusun dalam matriks deskripsi dan judgment. Untuk mengisi matriks tersebut, evaluator dapat mengumpulkan pertimbangan dari pengguna hasil evaluasi. Deskripsi data diklasifikan menjadi intent (tujuan yang diharapkan) dan keadaan yang observasi. Pernyataan judgmental diklasifikasikan pada keadaan yang memenuhi standar kualitas dan judgment khusus pada elemen program. Supaya lebih jelas, matriks data dapat diilustrasikan pada tabel 1 .

19 G F Madaus \& Stufflebeam, D. L. (Eds),Systematic Evaluation, Evaluation in Education and Human Services (Massachusetts: Chestnut Hill,1986),hlm.303.

20 B R Worthen \& Sanders, J. R,Educational Evaluation: Theory and Practice. (Worthington, Ohio: Charles A. Jones Publishing Company,1973),hlm.112-121. 


\section{Tabel 1}

Layout Data yang Dikumpulkan pada Responsive Evaluation

\begin{tabular}{|c|c|c|c|c|}
\hline & Observation & & Standard & Judgement \\
\hline \multirow{7}{*}{ 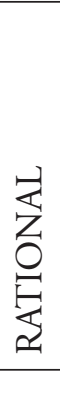 } & Anteceden yang diharapkan & Antecedent & Standard & Pertimbangan \\
\hline & dan yang dilaksanakan & & Anteceden & Anteceden \\
\hline & Transaksi yang diharapkan & Transaction & Standard & Perimbangan \\
\hline & dan yang dilaksanakan & & Transaksi & Transaksi \\
\hline & Outcome yang diharapkan & Outcome & Standard & Pertimbangan \\
\hline & dan yang dilaksanakan & & Dampak & Dampak \\
\hline & \multicolumn{2}{|l|}{ Description Matrix } & \multicolumn{2}{|c|}{ Judgement Matrix } \\
\hline
\end{tabular}

Sumber: Stufflebeam (1985: 218)

Ada dua cara prinsip yang dapat digunakan untuk memproses data evaluasi deskriptif pada program pendidikan, yaitu menemukan contingency (kemungkinan yang dapat terjadi) antara anteseden, transaksi, dan outcome serta congruence (kesesuaian) antara tujuan yang diharapkan dan kondisi yang diobservasi. Data kurikulum dikatakan congruence apabila tujuan yang diharapkan secara nyata terpenuhi. Dalam satu garis matriks data, evaluator dapat membandingkan sel-sel yang berisi tujuan dan observasi, untuk mencatat kesenjangan dan menjelaskan sebuah kongruens dengan garis tersebut. Kongruens tidak mengindikasikan outcome harus reliabel atau valid tetapi apakah yang diharapkan dapat terjadi.

Hasil analisis kesenjangan antara tujuan yang diharapkan dan kenyataan yang diobservasi kemudian dibandingkan dengan standar kualitas. Standar adalah kriteria minimum yang harus dipenuhi pada sebuah program/ kebijakan. Standar dapat ditetapkan pada saat merumuskan tujuan dan indikator keberhasilan. Ada dua tipe standar, yaitu standar relatif dan standar absolut. Standar relatif merupakan standar alternatif sebuah program yang dianggap dapat memuaskan dan standar absolut adalah standar mutlak yang harus ada dalam sebuah program. ${ }^{21}$ Standar merupakan benchmarks kinerja program atau kriteria yang menjadi pembanding untuk memutuskan program

21 Stufflebeam, op.cit.,hlm.222. 
telah sukses atau gagal. Program dikatakan efektif dan evaluasi dinyatakan lengkap apabila telah memenuhi standar yang ditetapkan.

Sebelum membuat judgment, evaluator menentukan masing-masing standar terlebih dahulu. Masing-masing standar diberi bobot sesuai dengan tingkat kepentingannya. Judgment diambil dengan cara membandingkan kesenjangan hasil observasi dengan tujuan yang diharapkan dan standar absolut yang telah ditetapkan oleh peneliti atau standar relatif pada program lain. Program dapat dinyatakan lebih baik dari program lain apabila hasil observasi lebih baik dari standar yang ditetapkan. Penggabungan judgment relatif dan absolut dapat dilakukan untuk membuat keputusan yang lebih rasional.

Secara umum Dunn (2003:610) menggambarkan enam kriteria evaluasi kebijakan public, yaitu meliputi kriteria efektivitas, efisiensi, kecukupan, perataan, responsivitas, dan ketepatan.

\section{Tabel 2}

Kisi-Kisi Instrumen Evaluasi BLU

\begin{tabular}{llll}
\hline Tahapan & Komponen & Aspek & Indikator \\
\hline Anteceden & $\begin{array}{l}\text { Dasar Pembuatan } \\
\text { Kebijakan }\end{array}$ & Dasar Empirik & Kecukupan \\
& Perumusan & Perencanaan & Ketepatan,kesesuaian \\
& Kebijakan & & Kesesuaian \\
& & Sarana prasarana & Kesesuaian,kecukupan \\
& & Konten & Kesesuaian,ketepatan \\
& & Persyaratan & Kesesuaian \\
& & Penetapan & Kesesuaian \\
\hline Transaction & Implementasi & Kelembagaan & Kesesuaian \\
& & Pengawasan & Responsivitas,ketepatan \\
& & Pengelolaan & Kesesuaian \\
& & Hubungan kerja & Kesesuaian
\end{tabular}




\begin{tabular}{llll}
\hline Tahapan & Komponen & Aspek & Indikator \\
\hline \multirow{4}{*}{ Outcome } & Kenghargaan & Kepatutan \\
& & Pelayanan & Responsivitas \\
\cline { 3 - 4 } & Keuangan & Pembatalan & Kesesuaian \\
& & Akuntansi & Kesesuaian \\
& & Pelaporan & Responsivitas \\
& & Pertanggungjawaban & Kesesuaian \\
\hline
\end{tabular}

\section{F. Penutup}

Kebijakan pemerintah mengeluarkan kebijakan reformasi di bidang pengelolaan keuangan membuktikan bahwa pola pengelolaan administrasi publik dalam era reformasi dan globalisasi yang bercorak desentralisasi dengan penekanan pada sumberdaya manusia sebagai unsur utama dalam pengembangan dinamika pengelolaan pelayanan publik sudah sesuai dengan semangat proses reformasi birokrasi di lingkungan instansi pelayanan publik. Pola pembiayaan yang sentralistik selama ini sangat dirasakan sebagai penghambat oleh banyak instansi pelayanan publik termasuk perguruan tinggi (PT) dalam pengambilan keputusan, di tengah dunia global yang begitu dinamis dimana arus modal, sumber daya dan tenaga kerja mengalir begitu cepat dari satu ke negara ke negara lain tanpa mengenal batas kedaulatan dan wilayah.

Situasi tersebut merupakan peluang dan sekaligus ancaman bagi setiap indivindu, kelompok maupun institusi. Bagi yang kreatif dan antisipatif, hal itu juga akan dengan mudah dalam mengubah ancaman menjadi peluang melalui pola korporasi untuk membentuk kekuatan dalam memenangkan persaingan. Namun, tidak demikian bagi yang tidak siap secara natural, mereka justru akan ditinggalkan atau bahkan menjadi lemah karena sumberdaya yang dimiliki termobilisasi ke tempat lain yang lebih menguntungkan. 


\section{DAFTAR PUSTAKA}

Anderson,James.E. 2009. Public Policy Making. New York: Holt Rinehart and Winston.

Cochran,C.E.,Meyer,L.C.,Carr.,Cayer,N.J.,2009, American Public Policy: An Introduction, $9^{\text {th }}$ edition. Wadssworth: Cengage-Learning.

Cronbach,L. 1982. Designing Evaluation of Educational and Social Programs. San Frasisco: Jossey-Bass.

Dunn, William N. 2003. Pengantar Analisis Kebijakan Publik. Jogjakarta:Gajah Mada University Press.

Edelenbos,J dan Van Buuren,A. 2005. The Learning Evaluation: A Theoritical and Empirical Exploration.Evaluation Review, 29(6):591-592.

Kahar,B. 2008. Excerpts from Review of Evaluation Frameworks. Saskatchewan Ministry of Education.

Keeley,J.,Scoones,I. 2003. Understanding Environmental Policy Processes: A Review. IDS Working Paper.

Madaus, G. F., \& Stufflebeam, D. L. (Eds),985. Systematic Evaluation, Evaluation in Education and Human Services. Massachusetts: Chestnut Hill.

Meter Van,Donald S dan Carl E. Van Horn. 1995. The Policy Implementation Process: A Conceptual Framework. Beverly Hills: Sage Publication.

Nugroho, Rian. 2007. Public Policy. Jakarta: PT. Elex Media Komputindo.

Owen,John. 2006. Program Evaluation, $3^{\text {rd }}$ edition. NSW: Allen and Unwin.

Preskill,Hallie dan Natalie Jones. 2009. Practical Guide for Engaging Stakeholder in Developing Evaluation Question. Princetown: Robert Wood Johnson Foundation.

Raphael,Baverley. 2011. Evaluation: A Guidefor Good Practices. Sidney:National Youth Suicide Prevention Strategy Evaluation Working Group.

Scriven,M. 1975. Evaluation Bias and Its Control.Uninersity California: Berkeley.

Setiawan, Agus.2016. "BLU: Akuntansi BLU dan Tantangan Kedepannya”Dalam http://www.ppkblu.depkeu.go.id/index.php, Diakses pada 28 Mei 2016. 
Shadish,W.R,CookT.D,Campbell,D.T. 1963.Experimental and QuasiExperimental Design for Generalized Causal Inference. Boston:Houghton Mifflin'.

Stake, Robert E. 2004. Standards-Based and Responsive Evaluation. London: Sage Publication.

Stufflebeam, Daniel L dan Shinkfield, Antony J. 2007. Evaluation Theory, Models and Application. San Fransisco: John Wiley and Sons Inc.

Worthen, B. R., \& Sanders, J. R. 1973. Educational Evaluation: Theory and Practice. Worthington, Ohio: Charles A. Jones Publishing Company 